\title{
Narrativas jornalísticas sobre o dia do fogo na Amazônia: O caso da Folha de S. Paulo (Brasil) e do Público (Portugal)
}

\begin{abstract}
Thaís Braga ${ }^{1}$ e Sandra Marinho ${ }^{1}$
${ }^{1}$ Centro de Estudos Comunicação e Sociedade da Universidade do Minho, Portugal | thaislcbraga@gmail.com; sandra.m.marinho@gmail.com | https://orcid.org/0000-0002-25057367; https://orcid.org/0000-0003-2013-229X

Resumo: O dia do fogo na Amazônia remete aos incêndios florestais que se espalharam do Brasil para outros países da América do Sul, em agosto de 2019. O artigo objetiva identificar e compreender quais foram as narrativas jornalísticas sobre o dia do fogo na Amazônia e como foram produzidas. Foram selecionados os jornais de língua portuguesa Folha de $S$. Paulo (Brasil) e Público (Portugal) para a observação e análise do caso. Como suporte teóricometodológico, recorreu-se à hermenêutica de profundidade (HP), que associa três estágios analíticos individuais e interdependentes: análise sócio-histórica, análise formal ou discursiva e reinterpretação. $\mathrm{Na}$ análise sócio-histórica, foram caracterizados: 1) a Amazônia, como fronteira socioeconômica; 2 ) o jornalismo, pela capacidade de articular os acontecimentos sob a forma de narrativa; 3 ) os jornais Folha de S. Paulo e Público, pela importância em cada país. $\mathrm{Na}$ análise formal ou discursiva, foram operacionalizados os procedimentos metodológicos: constituição do corpus por amostragem não probabilística de casos típicos; observação direta (grelha de análise) e observação indireta (entrevista semiestruturada em profundidade com os principais jornalistas do caso); e análise pragmática da narrativa jornalística. A partir dos seis movimentos previstos por esta técnica (recomposição da intriga; identificação dos conflitos e funcionalidade dos episódios; construção de personagens jornalísticas; estratégias comunicativas; relação comunicativa e o "contrato cognitivo"; metanarrativas), observou-se que as narrativas produzidas pela Folha de $S$. Paulo e pelo Público tiveram características próprias. Enquanto o jornal brasileiro configurou um conflito com começo, meio e fim, no jornal português a narrativa terminou em anticlímax. Na Folha de $S$. Paulo, predominou a ideia de impunidade dos crimes ambientais na Amazônia, já, no Público, evidenciou-se o lamento diante da perda de biodiversidade.
\end{abstract}

Palavras-chave: Amazônia; Hermenêutica de Profundidade; Análise Pragmática da Narrativa Jornalística; Folha de S. Paulo; Público.

Journalistic Narratives about the Day of Fire in the Amazon: The Case of Folha de S. Paulo (Brazil) and Público (Portugal)

Abstract: The day of fire in the Amazon refers to forest fires that spread from Brazil to other countries in South America, in August 2019. The article aims to identify and understand what the journalistic narratives about the day of fire in the Amazon were and how they were produced. The Portuguese-language newspapers Folha de S. Paulo (Brazil) and Público (Portugal) were selected for the observation and analysis of the case. As a theoreticalmethodological support, depth hermeneutics $(\mathrm{DH})$ was used, which combines three individual and interdependent analytical stages: socio-historical analysis, formal or discursive analysis and reinterpretation. In the socio-historical analysis, the following were characterized: 1) the Amazon, as a socioeconomic border; 2) journalism, due to the ability to articulate events in the form of a narrative; 3 ) the newspapers Folha de $S$. Paulo and Público, due to their importance in each country. In the formal or discursive analysis, the methodological procedures were operationalized: constitution of the corpus by non-probabilistic sampling of typical cases; direct observation (analysis grid) and indirect observation (in-depth semi-structured interview with the main journalists in the case); and pragmatic analysis of the journalistic narrative. From the six movements foreseen by this technique (recomposition of the story; identification of the conflicts and functionality of the episodes; construction of journalistic characters; communicative strategies; communicative relationship and the "cognitive contract", metanarratives), it was observed that the narratives produced by Folha de S. Paulo and by Público had their own characteristics. While the Brazilian newspaper configured a conflict with beginning, middle and end, in the Portuguese one the narrative ended in an anticlimax. In Folha de S. Paulo, the idea of impunity for environmental crimes in the Amazon prevailed, while, in Público, the sorrow was evident in the face of the loss of biodiversity.

Keywords: Amazon; Depth Hermeneutics; Pragmatic Analysis of the Journalistic Narrative; Folha de S. Paulo; Público. 


\section{Introdução}

Em 5 de agosto de 2019, o jornal brasileiro Folha do Progresso antecipou que fazendeiros, madeireiros e empresários dos arredores da BR-163 (rodovia longitudinal que conecta a região sul às regiões centro-oeste e norte do país), inspirados pelo presidente Jair Bolsonaro (2019-atual), planejavam atear fogo à floresta amazônica no dia 10 de agosto daquele ano. No dia previsto, a Amazônia brasileira foi tomada por uma série de incêndios que, ao logo daquele mês, se espalharam para Bolívia, Peru, Venezuela e Paraguai. O caso, conhecido como dia do fogo, foi descrito e narrado pelos media, cujos discursos revelaram não apenas representações da realidade, mas também ações desenvolvidas em função de estratégias culturais em contexto.

Assim, pergunta-se: quais foram as narrativas jornalísticas sobre o dia do fogo na Amazônia e como foram produzidas? Selecionaram-se os jornais Folha de S. Paulo (Brasil) e Público (Portugal) para a observação e análise do caso, uma vez que ambos afirmam compartilhar, além da língua portuguesa, uma cultura e um código de valores, nomeadamente o compromisso com a democracia, o Estado de direito e os direitos humanos (Carvalho, M. \& Dávila, 2020). Reitera-se que, em concordância com Noor (2008), um caso está relacionado a um acontecimento, uma entidade, um indivíduo ou mesmo uma unidade de análise. Trata-se de uma pesquisa empírica que investiga um fenômeno contemporâneo dentro de seu contexto da vida real. Portanto, o dia do fogo na Amazônia, analisado por meio de narrativas jornalísticas, consiste no método para se identificar e compreender os sentidos produzidos no Brasil e em Portugal.

\section{A Hermenêutica de Profundidade (HP) como Referencial Teórico-Metodológico}

Esta investigação (figura 1) insere-se no paradigma hermenêutico/qualitativo, pois se entende que a realidade e/ou os objetos que serão conhecidos não existem de maneira independente do sujeito conhecedor. Consoante Orozco \& González (2012), não existe uma realidade objetiva lá fora, impermeável ao pensamento e à visão do investigador ou da investigadora que quer compreendê-la. Coutinho (2014) explica que, além de parciais e inseridas em determinada perspectiva, as interpretações são circulares, interativas e em espiral, ou seja, a interpretação da parte depende da interpretação do todo, da mesma forma que o todo depende das partes. Considerando as narrativas jornalísticas sobre o dia do fogo na Amazônia uma construção simbólica significativa que exige uma interpretação, recorreu-se à hermenêutica de profundidade (HP), desenvolvida por Thompson (2011), como suporte teórico-metodológico. Chamada de metodologia da interpretação, a HP caracteriza-se por métodos particulares de análise que ajudam a iluminar alguns aspetos do fenômeno às custas de outros: "Esses métodos particulares podem ser melhor analisados como estágios parciais dentro de um enfoque metodológico mais abrangente" (Thompson, 2011, p. 33). De acordo com o sociólogo, as construções simbólicas são significativas não apenas porque são interpretadas e compreendidas pelas pessoas que as produzem e recebem, mas também porque são estruturadas de maneiras definidas e estão inseridas em condições sociais e históricas específicas. Para compreendê-las, a HP conjuga três procedimentos analíticos: 1) análise sócio-histórica, com vistas à reconstituição das condições sociais e históricas de produção, circulação e recepção de construções simbólicas; 2) análise formal ou discursiva, que objetiva identificar a estrutura articulada das construções simbólicas; 3) reinterpretação, que, facilitada pelas instâncias anteriores, desvela os padrões e sentidos que constituem e operam dentro das construções simbólicas: "A interpretação implica um novo movimento de pensamento, ela procede por síntese, por construção criativa de possíveis significados" (Thompson, 2011, p. 375). 


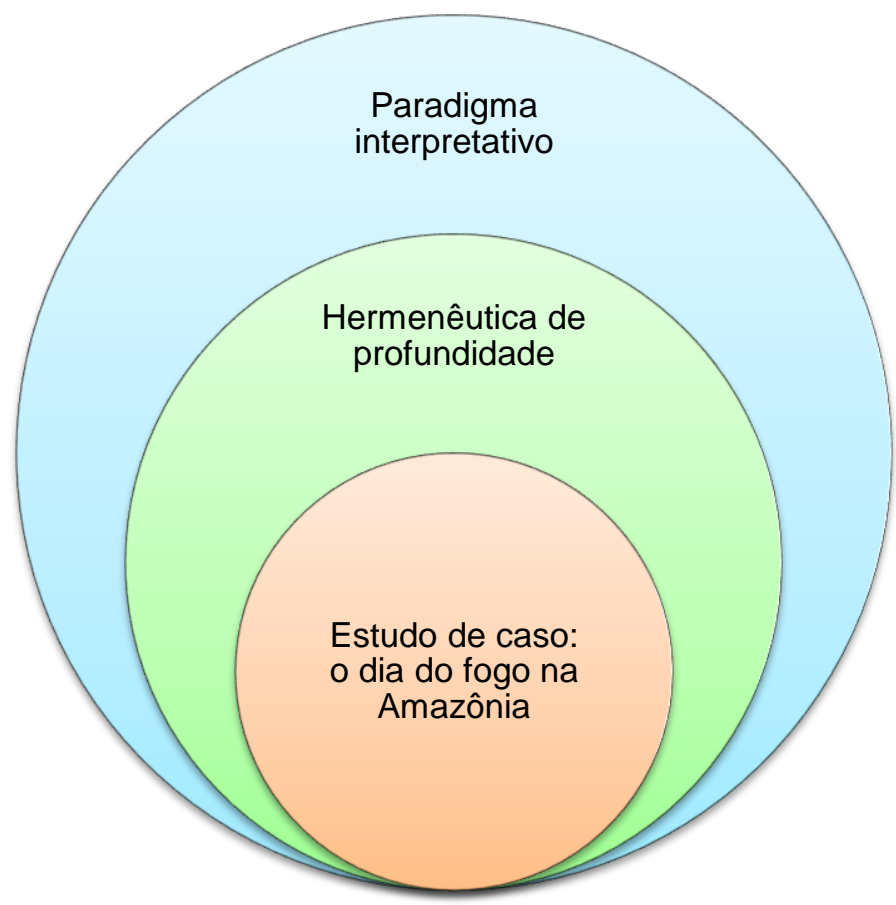

Fig. 1. Apreensão teórico-metodológica da investigação.

De maneira breve, indica-se que a análise sócio-histórica se dividiu em três instâncias. Primeiro, observou-se que o caso evidenciou o debate em torno da Amazônia não apenas como fonte de biodiversidade, mas principalmente como fronteira socioeconômica, uma vez que, mundialmente, prevalece a ideia de preservação para a sobrevivência do planeta Terra; nacionalmente, a floresta importa como área de expansão do povoamento e da economia brasileira a fim de garantir a soberania sobre o território; e, regionalmente, as elites procuram superar o "atraso" para se igualar às sociedades modernas (Dutra, 1999; Paes Loureiro, 1995). Em seguida, refletiu-se sobre a capacidade mediadora do jornalismo, ou seja, de relacionar o mundo da vida e o mundo do texto ao narrar os fenômenos percebidos, reconstituindo-os de modo singular por meio de um discurso específico (Freitas \& Benetti, 2017). Por fim, caracterizaram-se os jornais Folha de $S$. Paulo e Público a partir de certos indicadores, como a trajetória de crescimento desde a fundação, a circulação impressa e digital, bem como os princípios do manual de redação e estilo. Por ter-se escolhido as narrativas jornalísticas para a observação e análise do dia do fogo na Amazônia, destaca-se, a seguir, o movimento do discurso em direção à configuração narrativa.

\subsection{Do Acontecimento Discursivo às Narrativas Jornalísticas}

Para Quéré (2012), acontecimento trata-se de uma emergência que instaura sentidos, bem como rompe com a continuidade da experiência. É aquilo que "vem de fora, o que surge, o que acontece, o que se produz, o excepcional que se desconecta da duração" (Quéré, 2012, p. 21). Por isso, inscreve-se num contexto e ganha nova dimensão na medida em que é descrito e narrado pelos meios de comunicação social. Este processo, em geral, forja-se por meio de práticas e rotinas centradas na redação. Como consequência, o discurso jornalístico desprende-se das circunstâncias de enunciação e se torna uma palavra de mediação entre interlocutores e com o seu tempo "em torno de um 'terceiro' (o real, o Outro)" (França, 1998, p. 29). Para Babo-Lança (2006), não há acontecimento social sem descrição, tampouco sem narrativa. 
A descrição pode ser tratada como sinal ou testemunho da realidade, enquanto a narrativa dá conta das operações pelas quais os diferentes atores sociais configuram os acontecimentos, isto é, as maneiras de designá-lo, relatá-lo e caracterizá-lo, bem como os procedimentos empregados para o anunciar, denunciar, tematizar e construir em problema. O jornalismo torna-se capital para a descrição, explicação, categorização e narração dos acontecimentos, na medida em que reúne "maneiras de dizer" próprias dos jornalistas e de todos os que se ocupam em descrever, relatar e explicar o que aconteceu. Em termos narrativos, as ocorrências ligadas sob uma mesma trama ou intriga, bem como sob uma mesma identidade, formam um acontecimento único - cuja individualidade, para além do aspecto linguístico, advém do ponto de vista adotado e, também, da sua ocorrência localizada no tempo e no espaço. Desta forma, a narrativa não se trata apenas de uma lista de acontecimentos sem ligação. Por meio da intriga, opera-se uma conexão de tipo casual entre os acontecimentos, efetuando a transição entre contar e explicar. A intriga sintetiza elementos heterogêneos numa mesma trama, ou seja, ordena uma série de acontecimentos de maneira específica. Também, organiza a experiência temporal com vistas à ordenação da situação vivida. Ainda de acordo com Babo-Lança (2006), a experiência que se tem de uma série de ocorrências, de acasos, de circunstâncias, de resultados pretendidos ou inesperados é compreendida quando se consegue estabelecer uma ligação entre os vários elementos, conferindo-Ihes uma ordenação e um significado. Por isso, o acontecimento reporta-se ao passado e, ao mesmo tempo, introduz um novo estado de coisas ou irrompe uma nova situação. A narrativa ordena os acontecimentos em função do devir, uma vez que o passado é relativo ao surgimento dos acontecimentos no presente. Mesmo quando um acontecimento termina, o ponto final narrativo é, amiúde, provisório, pois o acontecimento pode ser reinterpretado de acordo com a maneira como será recebido; versões diferentes poderão ser propostas. Por conseguinte, os meios de comunicação social consistem em lugares privilegiados onde se configuram os acontecimentos. Numa perspectiva sociológica, o discurso mediático revela-o sob descrições e definições dos diversos atores sociais, reconstruindo e ampliando sentidos.

\section{Procedimentos Metodológicos}

A análise formal ou discursiva dividiu-se em duas instâncias, uma de natureza teóricometodológica e outra de exposição dos resultados. Esta seção concentra-se no primeiro item, ou seja, justificam-se as escolhas feitas na investigação (figura 2). Conforme já mencionado, o dia do fogo na Amazônia corresponde ao caso a ser analisado. De acordo com Zainal (2016, p. 1), como método de pesquisa robusto, os estudos de caso exploram e investigam determinado fenômeno da vida real "por meio da análise contextual detalhada de um número limitado de eventos ou condições e seus relacionamentos". Não havendo maneira única de compreender um caso, optou-se por analisá-lo a partir das narrativas jornalísticas. Assim, fez-se a restrição a componentes não estritamente representativos, mas característicos do universo. Selecionaram-se os textos produzidos pelos jornais Folha de S. Paulo e Público entre os meses de agosto de 2019 e setembro de 2020. Na área de pesquisa digital de cada jornal, buscou-se pela associação das palavras-chave "Amazônia", "incêndio" e "dia do fogo". Em especial, no Público, observou-se a grafia da primeira palavra tanto em português brasileiro ("Amazônia") como em português europeu ("Amazónia"). No total, foram escolhidos 60 textos da Folha de S. Paulo e 61 textos do Público, constituindo um corpus por amostragem não probabilística de casos típicos. 
Como técnicas/instrumentos de recolha de dados, adotou-se a observação direta ${ }^{1}$ (recolha de informações sem a interação com os sujeitos interessados por meio da grelha de análise) e a observação indireta (obtenção de informações por meio de entrevistas com os sujeitos interessados). Em concordância com Noor (2008), optou-se pelo formato semiestruturado de entrevistas em profundidade, dado a flexibilidade para abordar diferentes entrevistados de maneira diferente, abrangendo as mesmas áreas de coleta de dados. Na avaliação de Guion, Diehl, \& McDonald (2011), as entrevistas em profundidade são apropriadas para situações nas quais se deseja fazer perguntas abertas que suscitam profundidade de informações de relativamente poucas pessoas. Fraser \& Gondim (2004) explicam que a opção pelo formato semiestruturado concede liberdade ao entrevistado ou à entrevistada para discorrer sobre determinado assunto. Portanto, a grelha de análise permitiu caracterizar os textos jornalísticos sobre o dia do fogo na Amazônia a partir de certos indicadores, como gênero, retificação, tópicos, editoria, localidade, autoria, canais de fontes de informação e elementos visuais. Com base nessas informações, percebeuse que os jornalistas Phillippe Watanabe e Ricardo Cabral Fernandes foram os que mais produziram textos sobre o caso para a Folha de S. Paulo e para o Público, nesta ordem. Dadas as limitações impostas pela pandemia de covid-192, a entrevista a cada um deles foi realizada por meio do programa Skype, em dezembro de 2020, durante mais ou menos uma hora. Partiu-se de perguntas gerais, por exemplo, onde haviam se graduado e como começaram a trabalhar para os respectivos jornais, para perguntas específicas, como 0 que eles lembravam o dia do fogo na Amazônia, como ocorreu a apuração das informações e qual o peso do manual de redação e estilo na produção das notícias.

Para o tratamento dos dados, optou-se pela análise narrativa, pois, em concordância com Carvalho, A. (2000), a técnica privilegia a sequência temporal de uma ação, bem como as relações entre pressupostos ou causas e consequências. Na explicação da autora, a análise narrativa procura construir e dar sentido a uma história como um todo a partir dos fragmentos do discurso. Por conseguinte, esta forma de análise recusa fraturar tal estrutura em partes menores (por exemplo, em temas), bem como considera que uma história possui, pelo menos, três características: 1) os acontecimentos são estruturados numa sequência temporal; 2) deve existir uma coerência logica na história, ou seja, os acontecimentos devem estar relacionados por uma ideia ou princípio organizador; 3) uma história envolve mudança a determinada situação por meio de uma série de acontecimentos. Freeman (2015) acrescenta que o cerne da ideia de narrativa como um modo de compreensão reside na sua dimensão retrospectiva, ou seja, no fato de que as narrativas sempre e necessariamente envolvem olhar para trás, a partir de algum momento presente, e ver, no movimento dos acontecimentos, episódios que fazem parte de um todo maior. Ainda segundo o autor, o entendimento narrativo abraça a natureza histórica da realidade humana, dado que o olhar em retrospecto não consiste num impedimento ao conhecimento, mas sim numa incursão, num caminho para dimensões de significado que não podem ser encontradas de nenhuma outra maneira.

${ }^{1}$ A observação direta e a observação indireta ora mencionadas fazem parte de uma das sete etapas do procedimento de investigação proposto por Quivy \& Campenhoudt (2005). Trata-se de uma fase intermediária entre a construção dos conceitos e o exame dos dados utilizados. Não se deve confundir com a observação direta como método, que se baseia na observação visual e cujas variantes são a observação participante de tipo etnológico ou a observação não participante

2 Em 1 de dezembro de 2019, foi identificado o coronavírus da síndrome respiratória aguda grave 2 (SARSCoV-2), causador da covid-19 (coronavirus disease), em Wuhan, na província de Hubei, na China. A doença espalhou-se por todo o mundo e, até maio de 2021, mais de 158 milhões de pessoas haviam sido infectadas, dos quais mais de 3 milhões morreram, segundo o Johns Hopkins Coronavirus Resource Center. Os países mais atingidos pela doença, em números absolutos, tem sido Estados Unidos da América, Índia e Brasil. 
Mais do que entender "o que aconteceu quando", como na crônica histórica, o movimento de olhar para trás busca compreender "como acontecimentos e experiências podem estar relacionados entre si, talvez até assumindo a forma de um enredo, uma constelação de significado que se mantém unida, em alguma aparência de unidade, os fios díspares do passado" (Freeman, 2015, p. 28). Importante ressaltar que o entendimento narrativo é irrevogavelmente interpretativo, portanto, provisório.

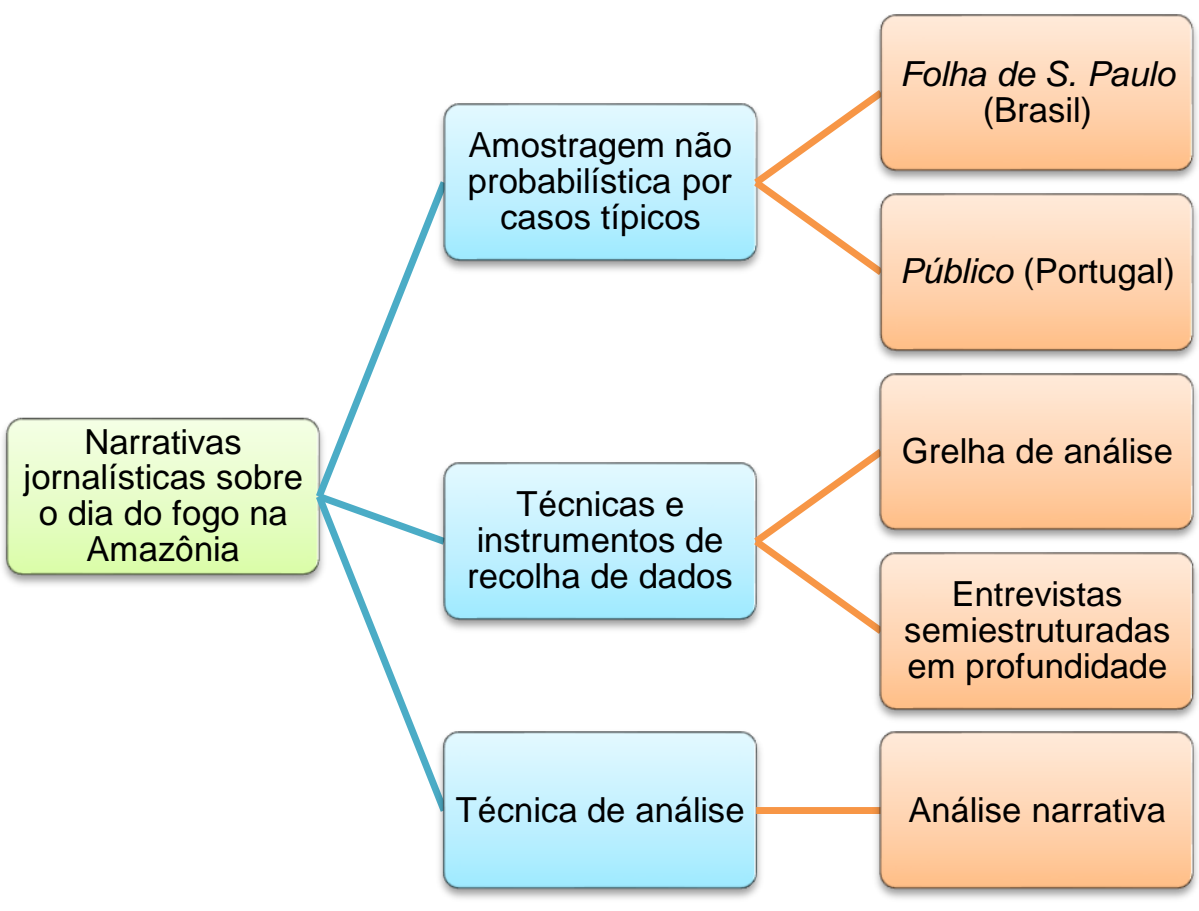

Fig. 2. Desenho do estudo de caso (o dia do fogo na Amazônia).

Operacionalizou-se, assim, a análise pragmática da narrativa jornalística, estruturada por Motta (2007). Num primeiro momento, pensa-se que não há narratividade, dado que os textos jornalísticos possuem uma unidade em si próprios. Contudo, ao integrar as notícias isoladas em um conjunto significativo solidário, obtém-se uma história única, ou seja, um acontecimento. Segundo o autor, não se trata de capricho, tampouco mera justificação metodológica. É mesmo assim que se move a mente da audiência: percebe-se e constróise, por meio da memória, a realidade social. Ademais, adotar o texto jornalístico como ponto de partida para estabelecer conexões e sínteses narrativas não significa se abster da análise do contexto comunicativo, uma vez que o texto jornalístico e suas significações são apenas os nexos entre $o$ ato de enunciar e $o$ ato de interpretar. A análise pragmática da narrativa jornalística propõe seis movimentos (figura 3) que visam "interpretar dinâmica e sistematicamente a essência do fenômeno observado", bem como "compreender as diversas camadas significativas do objeto empírico como objeto intencional de nossa percepção" (Motta, 2007, p. 147). Não há a necessidade de percorrer a ordem exata dos movimentos, uma vez que não se trata de um modelo, tampouco uma ordem gradual de aproximação. A única exigência a ser atendida é a exposição. Os movimentos são os seguintes: 1) recomposição da intriga ou acontecimento jornalístico, cujo objetivo é conectar as partes (as notícias fragmentadas pelas edições diárias dos jornais) e identificar a serialidade temática, bem como o encadeamento narrativo cronológico. A determinação do início e do fim da nova narrativa jornalística, que será recomposta pelo analista, é decidida de forma mais ou menos arbitrária, todavia não deve prescindir de rigor, coerência e justificação; 2) identificação dos conflitos e funcionalidade dos episódios. 
O autor explica que os conflitos, como elementos estruturadores da narrativa, abrem espaço para novas ações, sequências e episódios - os quais prolongam e mantêm a narrativa viva. Identificar os conflitos é o que permite discernir e compreender a funcionalidade dos episódios do novo enredo articulado pelo analista: "Episódios são unidades analíticas intermediárias que relatam conjuntos de ações relativamente autônomos (motivos) correspondentes às transformações no decorrer da história. Conectam-se ao todo, no qual significativamente se inserem. Devem receber nomes para designar essa funcionalidade" (Motta, 2007, p. 150); 3) construção de personagens jornalísticas (discursivas), cujo reconhecimento e dinâmica funcional relacionam-se diretamente com a identificação dos episódios. Isto porque as personagens são atores que realizam coisas, ou seja, atuam na progressão da história; 4) estratégias comunicativas, isto é, os dispositivos retóricos utilizados intencionalmente por repórteres e editores. Aqui, há a divisão em estratégias de objetivação (construção de efeitos de real) e estratégias de subjetivação (construção de efeitos poéticos); 5) relação comunicativa e o "contrato cognitivo", que significa observar o entorno ou a situação espaciotemporal onde as notícias são produzidas, bem como identificar supostas violações do "contrato cognitivo" implícito entre jornalistas e audiência - o qual se inspira pela objetividade e pelo entendimento do jornalismo como "lugar natural da verdade, o lugar do texto claro, isento, preciso e sem implicaturas nem suposições" (Motta, 2007, p. 164); 6) metanarrativas (significados de fundo moral ou fábula da história), dado que, se as notícias representam rupturas ou transgressões em relação a algum significado estável, cabe ao analista identificar, interpretar e elucidar as novas possibilidades.

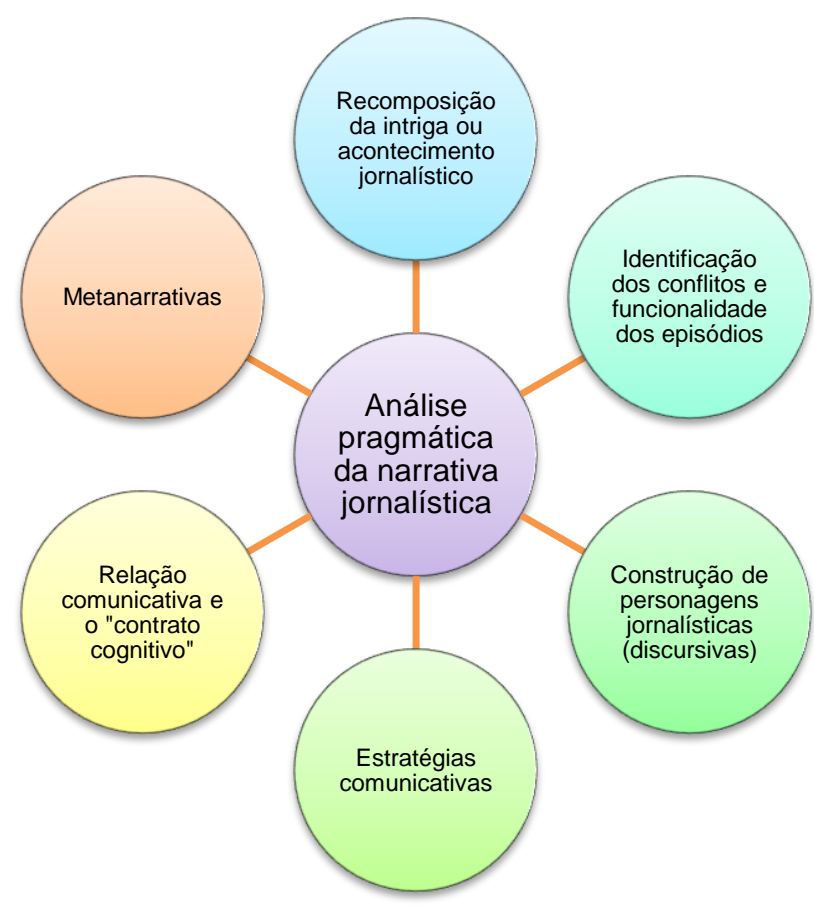

Fig. 3. Sem ordem pré-estabelecida, a única exigência da análise pragmática da narrativa jornalística é a exposição dos seis movimentos.

\section{Narrativas Jornalísticas sobre o Dia do Fogo na Amazônia}

Apresentam-se aqui os principais resultados da análise formal ou discursiva. Observou-se que o acontecimento produzido pela Folha de S. Paulo foi estruturado com começo, meio e fim. 
O início remeteu à série de desmontes feita pelo presidente Jair Bolsonaro aos órgãos de fiscalização e controle ambiental, como o Instituto Brasileiro do Meio Ambiente e dos Recursos Naturais Renováveis (Ibama) e o Instituto Chico Mendes de Conservação da Biodiversidade (ICMBio), além da acusação de que programa Queimadas, do Instituo Nacional de Pesquisas Espaciais (Inpe), divulgava dados falsos. O jornal brasileiro, apoiado no trabalho do jornalista Fabiano Maisonnave, que é correspondente em Manaus (AM), explicou que o dia do fogo se tratou de uma ação organizada por meio de um grupo de WhatsApp com vistas à queima da floresta para a criação agropecuária. Bolsonaro não apenas demorou a tomar qualquer atitude para conter o avanço das chamas, como permitiu que os envolvidos no crime ambiental seguissem impunes. Assim, os incêndios avançaram para outros biomas brasileiros: o Cerrado e o Pantanal. Para além do conflito principal, de natureza socioeconômica e política, foram estruturados mais seis episódios secundários, com funções: internacional, dado o confronto do presidente francês, Emmanuel Macron (2017-atual), com o homólogo brasileiro, além da acusação de Bolsonaro de que 0 ator estadunidense Leonardo DiCaprio financiava os incêndios florestais; de averiguação, já que muitas imagens falsas foram compartilhadas pelas redes sociais, inclusive pelo próprio Macron; econômica, que revelou a preocupação dos empresários da Amazônia e dos investidores estrangeiros; comportamental, que se dividiu em dois episódios: a busca dos internautas no Google e no Twitter por informações sobre o dia do fogo na Amazônia e a alteração no ritual de uma aldeia indígena, no Estado do Mato Grosso; e complicação, dado que o proprietário do jornal Folha do Progresso sofreu ameaças de morte por ter noticiado o planejamento da ação criminosa. No total, dez personagens jornalísticas constituíram a narrativa sobre o dia do fogo na Amazônia produzida pela Folha de S. Paulo: os "fazendeiros, madeireiros e empresários do entorno da BR-163", geralmente identificados desta forma indefinida; o presidente Jair Bolsonaro; o vice-presidente Hamilton Mourão; o ministro do meio ambiente, Ricardo Salles; o então presidente dos Estados Unidos, Donald Trump (2017-2021); o presidente Emmanuel Macron; o ator Leonardo DiCaprio; os investidores estrangeiros; os povos indígenas e o jornalista Adécio Piran, proprietário do Folha do Progresso. Entre as principais estratégias comunicativas, destacaram-se as infografias e os mapas como principais recursos de objetivação. As fotografias, geralmente fornecidas por agências de notícias, como a Reuters e a Agence France-Presse, funcionaram tanto como recursos de objetivação, como de subjetivação. Identificaram-se, ainda, memes e charges que enfatizaram as emoções da narrativa. Observou-se que a relação comunicativa da Folha de S. Paulo com o dia do fogo na Amazônia privilegiou o ponto de vista de São Paulo, sobretudo porque, segundo o jornalista Phillippe Watanabe, há uma divisão do trabalho: Fabiano Maisonnave apura os fatos in loco e, da capital paulista, Watanabe e os demais contextualizam o acontecimento. Também, o contrato cognitivo entre o periódico brasileiro e os leitores foi reforçado por meio das notícias destinadas à verificação dos fatos. Por fim, a principal metanarrativa recaiu sobre a ideia de que os crimes ambientais na Amazônia não são punidos.

Já o acontecimento produzido pelo Público terminou em anticlímax, pois se conheceu o começo e o meio, mas não o fim. Tal como a Folha de S. Paulo, o início remeteu aos desmontes dos órgãos de fiscalização e controle ambiental pelo governo Bolsonaro, porém não se identificaram os responsáveis pela organização do dia do fogo na Amazônia, apenas as consequências, especialmente a destruição da maior reserva de biodiversidade da Terra. O conflito principal, de caráter ambiental, foi menos apelativo do que os cinco episódios secundários, cujas funções foram de comoção, ao evidenciar o lamento de artistas, políticos e mesmo dos leitores do Público diante dos incêndios florestais; políticointernacional, pois enfatizou o antagonismo entre Jair Bolsonaro e Emmanuel Macron para além dos ataques pelo Twitter, com o segundo unindo-se a outros países da União Europeia (UE) para aplicar sansões econômicas ao Brasil; lusófona, dado que o governo português dividiu-se entre a solidariedade ao povo brasileiro e a tentativa de apaziguar os ânimos da UE; institucional, ao enfatizar a participação do governo brasileiro em fóruns internacionais, como as Assembleias-Gerais da Organização das Nações Unidas; e de protesto, que mostrou as manifestações nas principais cidades portuguesas (Lisboa e Porto), além de intervenções do Greenpeace, em frente ao Parlamento Europeu, em Bruxelas. 
Ao todo, cinco personagens jornalísticas constituíram a narrativa sobre o dia do fogo na Amazônia produzida pelo Público: os presidentes Jair Bolsonaro, Emmanuel Macron e Donald Trump, além da UE e dos ativistas do Greenpeace. O Público também utilizou mapas e infografias como estratégias de objetivação da narrativa, porém destacaram-se mesmo os recursos de subjetivação: além de fotografias (majoritariamente fornecidas pela Reuters) e de ilustrações, certas construções discursivas enfatizaram a tragédia ambiental, opondo a exuberância do verde da floresta ao vermelho das chamas. Observou-se que a relação comunicativa do periódico português com o dia do fogo na Amazônia estabeleceu-se à distância, com base principalmente em informações já divulgadas pelos media brasileiros (como a própria Folha de S. Paulo). Consonante o jornalista Ricardo Cabral Fernandes, o acontecimento foi inicialmente mais explorado por conta de uma oportunidade: o verão de 2019, quando parte dos jornalistas estava de férias. Tão logo encerrou-se o mês de agosto, o caso já não mais interessava à sociedade portuguesa. $O$ contrato cognitivo entre o jornal e os leitores foi quebrado em alguma medida, pois identificaram-se erros de apuração e de edição em alguns textos, além da insistência na metáfora errônea de Amazônia como "pulmão do mundo". Enfim, a principal metanarrativa apontou para o risco de a floresta amazônica não sobreviver para as próximas gerações.

\section{Conclusões}

Na etapa de reinterpretação das narrativas jornalísticas sobre o dia do fogo na Amazônia, percebeu-se alguma convergência de sentidos produzidos pelas sociedades brasileira e portuguesa. Em geral, a referência aos dados científicos não apenas para contraargumentar as declarações falsas ou imprecisas do presidente Jair Bolsonaro, mas também para enfatizar a importância da floresta para a manutenção da biodiversidade na Terra foi um denominador comum nos periódicos analisados. Os jornalistas Phillippe Watanabe e Ricardo Cabral Fernandes enfatizaram a importância da objetividade para a produção de um discurso livre de adjetivos, sobretudo quando os valores democráticos são ameaçados. Apoiada no trabalho dos correspondentes, a Folha de S. Paulo conseguiu produzir uma narrativa mais complexa e com melhor exploração dos recursos gráficos. Já - Público, que tratou o caso pela ótica da seção internacional, recorreu principalmente a outros media e a agências de notícias, por exemplo, Lusa e Reuters, como fontes. Ambos os jornais recorreram a perfis nas redes sociais para coletar informações sobre o caso, contudo a Folha de S. Paulo reforçou o contrato cognitivo ao verificar e contextualizar as fotos falsas sobre o dia do fogo na Amazônia. Em suma, pelo lado brasileiro, reiterou-se a impunidade dos crimes ambientais, sob a "bênção" do presidente Jair Bolsonaro, enquanto pelo lado português evidenciou-se o lamento diante da perda da floresta amazônica.

\section{Agradecimentos}

Este trabalho é financiado por fundos nacionais através da FCT - Fundação para a Ciência e a Tecnologia, I.P., no âmbito do projeto UIDB/00736/2020.

\section{Referências}

Babo-Lança, I. (2006). A configuração dos acontecimentos públicos: o "caso República" e as manifestações nos Açores em 1975. Coimbra: MinervaCoimbra.

Carvalho, A. (2000). Opções metodológicas em análise de discurso: instrumentos, pressupostos e implicações. Cadernos Do Noroeste: Série Comunicação, 14(1-2), 143-156. Retrieved from http://hdl.handle.net/1822/5520

Carvalho, M., \& Dávila, S. (2020, July 9). Carta aos leitores do PÚBLICO e da Folha de S. Paulo. Público. Retrieved from https://www.publico.pt/2020/07/09/opiniao/editorial/carta-leitorespublico-folha-spaulo-1923602 
Coutinho, C. P. (2014). Metodologia de investigação em ciências sociais e humanas: teoria e prática (2nd ed.). Coimbra: Almedina.

Dutra, M. (1999). O Pará dividido: discurso e construção do Estado do Tapajós. Belém: UFPA/NAEA/PLADES.

França, V. R. V. (1998). Jornalismo e a vida social: a história amena de um jornal mineiro. Belo Horizonte: Editora UFMG.

Fraser, M. T. D., \& Gondim, S. M. G. (2004). Da fala do outro ao texto negociado: discussões sobre a entrevista na pesquisa qualitativa. Paidéia (Ribeirão Preto), 14(28), 139-152. https://doi.org/10.1590/s0103-863x2004000200004

Freeman, M. (2015). Narrative as a mode of understanding: method, theory, praxis. In A. De Fina \& A. Georgakopoulou (Eds.), The Handbook of Narrative Analysis (pp. 21-37). Sussex: WileyBlackwell.

Freitas, C., \& Benetti, M. (2017). Alteridade, outridade e jornalismo: do fenômeno à narração do modo de existência. Brazilian Journalism Research, 13(2), 10-29. https://doi.org/https://doi.org/10.25200/BJR.v13n2.2017.989

Guion, L. A., Diehl, D. C., \& McDonald, D. (2011). Conducting an In-depth Interview. Retrieved from https://www.betterevaluation.org/en/resources/guide/conducting_an_in-depth_interview

Motta, L. G. (2007). A Análise Pragmática da Narrativa Jornalística. In C. Lago \& M. Benetti (Eds.), Metodologias de pesquisa em jornalismo (pp. 143-167). Petrópolis: Vozes.

Noor, K. B. M. (2008). Case study: A strategic research methodology. American Journal of Applied Sciences, 5(11), 1602-1604. https://doi.org/10.3844/ajassp.2008.1602.1604

Orozco, G., \& González, R. (2012). Una coartada metodológica: abordajes cualitativos en la investigación en comunicación, medios y audiencias. México: Tintable.

Paes Loureiro, J. de J. (1995). Cultura Amazônica: uma poética do imaginário. Belém: Cejup.

Quéré, L. (2012). A dupla vida do acontecimento: por um realismo pragmatista. In V. R. V. França \& L. de Oliveira (Eds.), Acontecimento: reverberações. Belo Horizonte: Autêntica.

Quivy, R., \& Campenhoudt, L. (2005). Manual de investigação em ciências sociais - Trajectos (4th ed.). Lisboa: Gradiva.

Thompson, J. B. (2011). Ideologia e cultura moderna: teoria social crítica na era dos meios de comunicação de massa (9th ed.). Petrópolis: Vozes.

Zainal, Z. (2016). Case Study As a Research Method. Jurnal Kemanusiaan, 5(1), 1-6. Retrieved from: https://jurnalkemanusiaan.utm.my/index.php/kemanusiaan/article/view/165/158 